\title{
Insulin Administration Alters Gonadal Steroid Metabolism Independent of Changes in Gonadotropin Secretion in Insulin-resistant Women with the Polycystic Ovary Syndrome
}

\author{
Andrea Dunaif and Margaret Graf \\ Departments of Medicine and Obstetrics, Gynecology, and Reproductive Science, Mount Sinai School of Medicine of The City \\ University of New York, New York, New York 10029
}

\begin{abstract}
We have investigated the hypothesis that hyperinsulinemia may cause the polycystic ovary syndrome (PCO) by directly stimulating gonadal steroidogenesis and/or gonadotropin secretion. 10 insulin-resistant women with PCO and 5 age- and weight-matched ovulatory normal women had pulsatile gonadotropin release, gonadotrope sensitivity to gonadotropin-releasing hormone, and sex hormone levels studied on two consecutive study days, basally and during the infusion of insulin (mean \pm SEM steady state insulin levels, $1,254 \pm 63 \mu \mathrm{U} / \mathrm{ml}$ PCO vs. $907 \pm 92 \mu \mathrm{U} / \mathrm{ml}$ normal, $P \leq 0.01)$. Insulin acutely increased mean delta (6 h minus prestudy) levels of androstenedione $(\mathrm{A})(P \leq 0.001)$ and estradiol $\left(\mathrm{E}_{2}\right)(P \leq 0.05)$ and decreased mean plasma pool (0-6 h) levels of testosterone $(T)$ $(P<0.05)$, nonsex hormone binding globulin-bound T $(P$ $<0.05)$, and dihydrotestosterone $(P \leq 0.01)$ in the $P C O$ women. Insulin also decreased mean plasma $6 \mathrm{~h} A$ to estrone $\left(E_{1}\right)$ ratios and increased $6 h E_{1}$ levels (both $P \leq 0.05$ ) in the PCO women. There were significant sequence effects (insulin + day) in the $\mathrm{PCO}$ women on $\mathrm{T} / \mathrm{E}_{2}$ ratios, indicating a carryover action of insulin. Insulin had no effects on gonadotropin release in the PCO women. In the normal women, the only significant change was an insulin or study day effect that increased mean 6 h $\mathrm{E}_{2}$ levels $(P \leq 0.01)$. There were significant spontaneous decreases in mean luteinizing hormone $(P<0.05)$ and follicle-stimulating hormone levels $(P \leq 0.01)$ in the PCO but not the normal women on the second day of study. This study indicates that insulin can directly alter peripheral sex hormone levels independent of changes in gonadotropin release in insulin-resistant PCO women. Insulin decreased the levels of potent androgens in PCO women and did not increase androgen levels in normal women, arguing against a simple, direct causal relationship between hyperinsulinemia and hyperandrogenism in PCO.
\end{abstract}

\section{Introduction}

The polycystic ovary syndrome (PCO) ${ }^{1}$ is a common endocrine disorder of unknown etiology characterized by its bio-

This work was presented in part at the 69th Annual Meeting of the Endocrine Society, Indianapolis, IN, June 1987: (Abstr. 848.)

Address reprint requests to Dr. Andrea Dunaif, Department of Medicine, Division of Endocrinology, Box 1055, Mount Sinai School of Medicine, 1 Gustave L. Levy Place, New York, NY 10029.

Received for publication 11 January 1988 and in revised form 25 July 1988.

1. Abbreviations used in this paper: A, androstenedione; BMI, body mass index; DHEAS, dehydroepiandroesterone sulfate; DHT, dihy-

J. Clin. Invest.

(C) The American Society for Clinical Investigation, Inc. 0021-9738/89/01/0023/07 \$2.00

Volume 83, January 1989, 23-29 chemical abnormalities: disordered gonadotropin secretion and hyperandrogenism $(1,2)$. Basal and glucose-stimulated hyperinsulinemia have recently been recognized as features of PCO and significant positive correlations between insulin and androgen levels have been found in several studies (3-6). These observations have led to the hypothesis that hyperinsulinemia causes hyperandrogenism via direct stimulation of gonadal steroidogenesis and/or gonadotropin secretion (4-9). Indeed, hyperandrogenism occurs in a number of distinct syndromes of extreme insulin resistance (10-13) and has developed in premenopausal women with the type B syndrome (7).

There are several possible mechanisms whereby insulin might play a role in the development of PCO. Specific receptors for insulin and insulin-like growth factors have been found in animal and human ovarian tissues $(14,15)$ as well as in rat hypothalamus and pituitary $(16,17)$. These peptides are also known to have a number of actions on gonadal steroidogenesis in vitro $(15,18)$. Further, insulin can cross the bloodbrain barrier in man (19) and can stimulate luteinizing hormone (LH) and follicle-stimulating hormone (FSH) release from rat pituitary cells in vitro (20). Many gonadal insulin actions, however, appear to be mediated through the insulinlike growth factor I (IGF-I) receptor rather than the insulin receptor $(15,18)$. This is consistent with the observation that insulin in large doses can stimulate androgen production in stromal tissue in vitro from ovaries of hyperandrogenic women with insulin resistance (21), indicating that this insulin action is preserved, despite resistance to insulin actions on carbohydrate metabolism.

The effects of prolonged insulin administration on sex hormone levels in vivo have been examined twice, with conflicting results $(22,23)$. These studies, however, included few hyperandrogenic women and neither case specified whether these women fulfilled the diagnostic criteria for PCO. This latter point is of central importance because in vitro studies $(21,24)$ suggest that such PCO-associated changes as ovarian stromal hyperplasia and $\mathrm{LH}$ hypersecretion greatly enhance insulin action on steroidogenesis. Further, women with PCO are also hyperinsulinemic and could thus be expected to be insulin primed.

Exploring the effects of insulin in PCO may thus shed light not only on the pathogenesis of PCO but also on the newly appreciated relationship between insulin and reproductive function. Accordingly, we performed this study to investigate the following questions. (a) Does insulin contribute (by acting through its own or the IGF-I receptor $[15,18])$ to the abnormalities of gonadal steroidogenesis (e.g., hyperandrogenism) or gonadotropin secretion (e.g., increased LH release) that

drotestosterone; $\mathrm{E}_{1}$, estrone; $\mathrm{E}_{2}$, estradiol; F, cortisol; GnRH, gonadotropin-releasing hormone; OGTT, oral glucose tolerance test; $\mathrm{P}$, progesterone; PCO, polycystic ovary syndrome; SHBG, sex hormone binding globulin; uT, non-SHBG bound testosterone. 
occur in PCO? (b) What is (or are) the mechanism(s) of insulin action(s) on reproductive hormones?

\section{Methods}

Subjects. 10 hyperinsulinemic insulin-resistant women with PCO and 5 age- and weight-matched normal ovulatory women were selected for study. All women were aged 17-35 yr, in good health and euthyroid, and none had taken any medication known to affect gonadal function or carbohydrate metabolism for at least 3 mo before study. No woman had impaired glucose tolerance by the National Diabetes Data Group criteria (25) on an oral glucose tolerance test (OGTT) with a $40 \mathrm{~g} / \mathrm{m}^{2}$ glucose load.

The diagnosis of PCO was made when an elevation of one or more plasma androgen levels was associated with oligo- or amenorrhea since menarche (one woman, Patient 10 , had primary amenorrhea) $(2,26)$. Ovarian morphology was not assessed as this is a nonspecific finding $(27,28)$. Cushing's syndrome, androgen-secreting neoplasms, attenuated 21-hydroxylase deficiency (29), and hyperprolactinemia were excluded before PCO was diagnosed. All PCO women had basal and/ or glucose-stimulated hyperinsulinemia during the OGTT, based on our previously reported criteria (26), indicative of insulin resistance. 9 of the 10 PCO women had acanthosis nigricans diagnosed by the presence on clinical examination of papillomatous hyperpigmentation on the neck or in the axillae (26). We have shown that such PCO women have significantly higher glucose-stimulated insulin levels but similar patterns of pulsatile gonadotropin secretion and sex hormone levels compared with PCO women lacking this dermatologic change $(26,30)$. Acanthotic PCO women can thus be considered as a subgroup of PCO.

The normal women had 27-32-d regular menstrual cycles with ovulation confirmed by appropriately elevated luteal-phase progesterone levels and by daily blood sampling for gonadotropin levels in four of the five women. None of the normal women were hirsute or had acanthosis nigricans. The studies were performed during a time of documented anovulation in the PCO women and in the midfollicular phase of the cycle on days 5-10 in the normal women. The studies were approved by the Mount Sinai School of Medicine Institutional Review Board and written informed consent was obtained from each woman before the study.

Study design. All women ate a $300-\mathrm{g}$ carbohydrate diet for $3 \mathrm{~d}$ before the study and were admitted to the Mount Sinai Hospital General Clinical Research Center the day before the start of testing. The study was performed on two consecutive days after a 10-12-h overnight fast each night. In the PCO women, insulin administration was randomized because our previous studies (31) had shown spontaneous decreases in FSH levels in PCO women on the second day of a twoconsecutive-day study. Five $\mathrm{PCO}$ women thus received insulin on day 1 (day 1 insulin PCO group) and five PCO women received it on day 2 (day 2 insulin PCO group). After preliminary analysis of the data in the PCO women, five normal women were studied without randomization to control for the acute effects of insulin administration and the independent effect of PCO. The normal women all received insulin on day 2. All women remained at bed rest and fasting during each day of study. They ate a mixed meal containing at least $200 \mathrm{~g}$ of carbohydrate after completion of the first day of study.

On the control study day without insulin administration, an intravenous catheter was inserted at least $30 \mathrm{~min}$ before the start of blood testing. The catheter was maintained patent by a continuous slow infusion of isotonic saline containing $1 \mathrm{U}$ heparin/ml. Blood sampling was begun between 0830 and $0930 \mathrm{~h}$ at 10-min intervals for $6 \mathrm{~h}$ followed by the administration of gonadotropin-releasing hormone (GnRH; $10 \mu$ g i.v.) (Factrel; Ayerst Laboratories, New York, NY) and continued blood sampling at 10,20,60, and $120 \mathrm{~min}$ after the GnRH. An increased volume of blood was obtained just before starting the 10-min sampling (prestudy sample) and at $6 \mathrm{~h}$ before $\mathrm{GnRH}$ administration (6-h sample). On the insulin infusion day of study, insulin
(Humulin R; E. Lilly \& Co., Indianapolis, IN) was administered in a dose of $200 \mathrm{mU} / \mathrm{m}^{2}$ per min by the euglycemic hyperinsulinemic clamp technique (32). A primed continuous infusion of insulin was begun between 0830 and $0900 \mathrm{~h}$ using an infusion pump (Harvard Instruments, Natick, MA). A variable infusion of $20 \%$ dextrose was begun $4 \mathrm{~min}$ after the start of the insulin infusion via an infusion pump (IMED Corp., San Diego, CA) and the rate was adjusted according to every 5-min plasma glucose determination to maintain the plasma glucose concentration at the fasting level (32). A supplemental infusion of potassium phosphate was given to prevent hypokolemia and hypophosphatemia (33). 30 min after the start of insulin infusion when steady state insulin levels were achieved (32), blood sampling identical to that done on the control day of study was begun. Blood samples were also obtained basally and every 20-30 min during the insulin infusion for insulin levels. The insulin and glucose infusions were continued until all the blood sampling was completed (i.e., $81 / 2 \mathrm{~h}$ ).

Analytical methods. Plasma glucose was determined by the glucose oxidase technique using a glucose analyzer (model 2; Beckman Instruments, Fullerton, CA). Serum insulin levels were determined by RIA (26). Plasma LH and FSH levels were determined in a double-antibody RIA (31) in the 10-min samples and in the 10-, 20-, 30-, 60-, and 120-min samples obtained after GnRH. The LH and FSH levels are reported in micrograms per liter of LER-907. A pool was made from equal aliquots of plasma from every other 10-min sample (i.e. every 20 minutes) obtained from time 0 to $6 \mathrm{~h}$. The pools, the prestudy samples, and the 6-h samples were assayed for plasma levels of testosterone (T), dihydrotestosterone (DHT), androstenedione (A), dehydroepiandrosterone sulfate (DHEAS), estrone $\left(E_{1}\right)$, and estradiol $\left(E_{2}\right)$ according to previously reported methods (31). Cortisol (F), sex hormone binding globulin (SHBG), and non-SHBG bound testosterone (uT) levels were determined in the plasma pools $(31,34)$. Progesterone $(P)$ levels were determined in the plasma pools to assess the presence of recent ovulation (31). All samples for every hormone from each woman were assayed together to avoid interassay variation.

Data analysis. The 0-6 h, every 10-min LH and FSH levels were analyzed for the presence of pulses as previously reported (31). The means of the LH and FSH levels from 0 to $6 \mathrm{~h}$ were determined to reflect the integrated gonadotropin output over the $6 \mathrm{~h}$ and the maximal LH and FSH change from baseline after $10 \mu \mathrm{g}$ i.v. GnRH, was determined to reflect gonadotrope sensitivity to GnRH (31). Twogroup comparisons were made by paired or unpaired $t$ tests or nonparametric tests, as appropriate, and three group comparisons by analysis of variance (35). Repeated measures of analysis of variance (35) were performed to determine the effects of insulin administration, study day and study sequence (insulin on day 1 vs. insulin on day 2) in the day 1 insulin PCO group as compared with the day 2 insulin PCO group. In this analysis, a significant insulin effect indicated an insulin action, a significant day effect indicated that the changes were related to the day of study (e.g., spontaneous), and a significant sequence effect suggested that there was a carryover action of insulin.

Repeated measures of analysis of variance were also performed to compare the day 2 insulin PCO group with the day 2 insulin normal group. Under these circumstances, the analysis determined differences between PCO versus normal, the interaction of these two groups, and the effect of insulin or study day. It was not possible to differentiate an insulin effect from a study day effect (e.g., spontaneous hormone change on study day 2) because the day of insulin administration was not randomized in this part of the study. However, paired $t$ testing was performed to determine which of the groups (day 2 PCO or normal) showed significant changes on study day 2 .

The mean LH and FSH levels, pulse amplitudes (0-6 h), pulse frequency per $6 \mathrm{~h}$ and maximal responses to GnRH and steroid hormone levels from the plasma pools and the $6 \mathrm{~h}$, prestudy, and $6 \mathrm{~h}$ minus prestudy (delta) sex hormone levels were compared (except $P$ levels). In the day 1 insulin PCO group, the study day 2 prestudy and 6-h samples were obtained $\sim 16$ and $\sim 22 \mathrm{~h}$, respectively, after the insulin infusion was stopped and thus may have shown an insulin action from the previous day (i.e. carryover). Statistical calculations 
were performed using the CLINFO and SAS software systems (CLINFO, General Clinical Research Center Branch, National Institutes of Health, Bethesda, MD; SAS, Statistical Analysis Systems, Cary, NC). All data are reported as mean \pm SEM.

\section{Results}

Clinical features and glucose and insulin levels (Table I). All of the PCO women were hirsute and most were obese (body mass index $(B M I) \geq 28 \mathrm{~kg} / \mathrm{m}^{2}$ ); the mean $B M I$ in the normal women did not differ significantly from the PCO women. The mean basal venous plasma glucose concentration did not differ in the PCO and the normal women and was $97 \pm 2 \mathrm{mg} / \mathrm{dl}$ for the entire group $(n=15)$. The glucose concentration was clamped at $97 \pm 2 \mathrm{mg} / \mathrm{dl}$ with a coefficient of variation of $8 \pm 1 \%$. Basal serum insulin levels were increased in the $P C O$ women compared with the normal women (PCO 29 $\pm 5 \mu \mathrm{U} / \mathrm{ml}$ vs. normal $16 \pm 4 \mu \mathrm{U} / \mathrm{ml}, P>0.05$ ), but this change did not achieve statistical significance. Steady state serum insulin concentrations of $1,254 \pm 63 \mu \mathrm{U} / \mathrm{ml}$ in the PCO women and $907 \pm 92 \mu \mathrm{U} / \mathrm{ml}$ in the normal women were achieved during the insulin infusion. These levels differed significantly $(P$ $\leq 0.01$ ), perhaps secondary to decreased insulin clearance in the PCO women (36), although the metabolic clearance rate of insulin was not measured. The mean coefficient of variation for steady-state insulin levels during the clamp was $15 \pm 1 \%$.

Sex hormone and SHBG levels (Table II). There were no significant differences in day 1 prestudy sex hormone levels (before any insulin was administered) in the two PCO groups. There were significant increases in plasma A $(P \leq 0.01), \mathrm{T}(P$ $\leq 0.001)$, uT $(P \leq 0.001)$, DHT $(P<0.05)$, and $\mathrm{E}_{1}(P \leq 0.01)$ levels and significant decreases in plasma SHBG levels $(P$ $\leq 0.01$ ) in the PCO women compared with the normal women compatible with the biochemical profile of PCO $(1,2)$. Mean plasma $E_{2}$ levels were in the midfollicular range and did not

Table I. Clinical Features and Fasting Insulin Levels

\begin{tabular}{cccccc}
\hline Subject & Age & BMI & Hirsutism* & $\begin{array}{c}\text { Acanthosis } \\
\text { nigricans }\end{array}$ & $\begin{array}{c}\text { Fasting } \\
\text { insulin }\end{array}$ \\
\hline PCO & $y$ & $k g / m^{2}$ & & & $\mu U / m l$ \\
1 & 24 & 29.3 & $3+$ & + & 15 \\
2 & 25 & 31.1 & $3+$ & + & 23 \\
3 & 25 & 29.5 & $3+$ & + & 18 \\
4 & 29 & 32.3 & $1+$ & + & 53 \\
5 & 26 & 23.5 & $1+$ & 0 & 21 \\
6 & 21 & 41.5 & $3+$ & + & 63 \\
7 & 30 & 23.6 & $1+$ & + & 24 \\
8 & 23 & 33.8 & $1+$ & + & 13 \\
9 & 27 & 30.2 & $1+$ & + & 26 \\
10 & 17 & 28.3 & $3+$ & + & 35 \\
Mean \pm SEM & $25 \pm 1$ & $30.3 \pm 1.6$ & & & $29 \pm 5$ \\
Normal $(n=5)$ & & & & & \\
Mean \pm SEM & $28 \pm 2$ & $33.1 \pm 4.3$ & 0 & 0 & $16 \pm 4$ \\
Range & $23-35$ & $24.8-48.9$ & & & $7-25$ \\
$P$ & $>0.05$ & $>0.05$ & ND & ND & $>0.05$ \\
& & & & & \\
\hline
\end{tabular}

$* 1+$, sparse terminal hairs on face; $2+$, moderate to severe terminal hairs on face; $3+$, trunk terminal hairs in addition to facial terminal hairs.

¥ To convert to picomoles per liter, multiply by 7.175 . differ in the PCO and normal women. The ratio of the aromatase precursor/product pair, $\mathrm{T} / \mathrm{E}_{2}$, was significantly increased $(P \leq 0.01)$ in $\mathrm{PCO}$ women, whereas the ratio of the other pair, $A / E_{1}$, was similar in the PCO and normal women.

In the PCO women, insulin acutely increased $A$ and $E_{2}$ levels (Fig. 1), as indicated by significant insulin effects on mean plasma 6-h A $(P \leq 0.001)$, delta A $(P \leq 0.001)$ ( 7 of 10 PCO women with increased 6-h A levels), and delta $\mathrm{E}_{2}$ levels ( $P$ $<0.05$ ) (9 of $10 \mathrm{PCO}$ women with increased 6-h $\mathrm{E}_{2}$ levels). There were significant sequence effects (insulin + day) on $T / E_{2}$ ratios (Fig. 1) resulting in decreased mean delta $\mathrm{T} / \mathrm{E}_{2}$ ratios $(P$ $<0.05)$ and 6-h $\mathrm{T} / \mathrm{E}_{2}$ ratios $(P<0.05)$ (9 of $10 \mathrm{PCO}$ women with decreased 6-h $\mathrm{T} / \mathrm{E}_{2}$ ratios), indicating a carryover effect of insulin. Prestudy $A$ and $E_{2}$ levels were increased on the day after insulin administration in the day 1 insulin PCO group, and the day effects for these changes were significant for A ( $P$ $<0.05)$ and $\mathrm{E}_{2}(P<0.05)$. The sequence effect for the mean prestudy $\mathrm{T} / \mathrm{E}_{2}$ ratio was significant $(P \leq 0.01)$, consistent with a carryover effect of insulin (Fig. 1). Mean $T / E_{2}$ ratios, $A$, and $E_{2}$ levels had returned to baseline (Fig. 1) in the day 1 insulin PCO group by $6 \mathrm{~h}$ on study day 2 (i.e., $\sim 22 \mathrm{~h}$ after insulin). In the day 2 insulin PCO group, there was minimal spontaneous change in hormone levels on day 1 (Fig. 1). There were no significant changes in mean plasma pool $T / E_{2}$ ratios and $A$, and $\mathrm{E}_{2}$ levels (Table II).

Insulin acutely decreased T ( 7 of 10 PCO women), uT (8 of 10 PCO women), and DHT (8 of 10 PCO women) levels in the PCO women as indicated by the slight but significant decreases in these hormone levels in the plasma pools $(P<0.05-\leq 0.01)$ (Fig. 2, Table II) during insulin infusion. Study sequence and study day effects were not significant. There were no significant effects of insulin, study day or study sequence on prestudy, $6 \mathrm{~h}$, or delta values for T, uT, or DHT (data not shown). Thus there was no evidence for a continued action of insulin on these steroids.

Prestudy and 6-h $\mathrm{E}_{1}$ levels showed significant insulin effects (both $P \leq 0.01$ ). This resulted in increased prestudy and 6-h $\mathrm{E}_{1}$ levels in the day 1 insulin PCO group on the day after insulin infusion, suggesting a carryover action, although the sequence effects were not significant (Fig. 3). Conversely, in the day 2 insulin PCO group, there were minimal differences in the day 1 and day $2 E_{1}$ levels (Fig. 3) at these time points. The mean $A / E_{1}$ ratio showed significant insulin effects prestudy and at $6 \mathrm{~h}(P<0.05$ and $\leq 0.01$, respectively $)$. Although sequence effects were not significant, $A / E_{1}$ values were substantially lower in the day 1 insulin PCO group on day 2 prestudy ( $\sim 16 \mathrm{~h}$ after insulin) and continued to decrease at 6 $\mathrm{h}(\sim 22 \mathrm{~h}$ after insulin) than in the day 2 insulin PCO group (Fig. 3), suggesting that this change represented an insulin carryover action. The mean delta $E_{1}$ and $A / E_{1}$ values did not achieve statistical significance. There were no evident spontaneous changes in these hormone levels in the day 2 insulin PCO group on the day without insulin infusion (i.e., day 1).

The only significant overall change in sex hormone levels noted when the day 2 insulin PCO women were compared with the normal women was a significant insulin or study day effect on $6 \mathrm{~h} \mathrm{E}_{2}$ levels $(P \leq 0.01)$ (five of five PCO women and five of five normal women with increased 6-h $E_{2}$ levels). Significant interactions were noted on prestudy $(P \leq 0.01)$ and 6-h $(P \leq 0.01) \mathrm{T} / \mathrm{E}_{2}$ ratios (data not shown), because $\mathrm{E}_{2}$ levels increased in both groups, decreasing $T / E_{2}$ ratios. Only 6-h $E_{2}$ levels increased significantly when the control and insulin in- 
Table II. Steroid and SHBG Levels in the Plasma Pools

\begin{tabular}{|c|c|c|c|c|c|c|c|c|}
\hline & \multicolumn{5}{|c|}{ PCO } & \multicolumn{3}{|c|}{ Normal } \\
\hline & Insulin day 1 & Control day 2 & Control day 1 & Insulin day 2 & $P$ & Control day 1 & Insulin day 2 & $P$ \\
\hline $\mathrm{A}(n g / d l)$ & $203 \pm 29$ & $231 \pm 47$ & $184 \pm 29$ & $182 \pm 39$ & $>0.05$ & $65 \pm 9$ & $67 \pm 8$ & $\leq 0.01^{*}$ \\
\hline $\mathrm{T}(n g / d l)$ & $48 \pm 7$ & $61 \pm 6$ & $56 \pm 3$ & $54 \pm 5$ & $<0.05^{\ddagger}$ & $15 \pm 2$ & $13 \pm 2$ & $\leq 0.001^{*}$ \\
\hline $\mathrm{uT}(n g / d l)$ & $21 \pm 2$ & $28 \pm 5$ & $24 \pm 3$ & $21 \pm 2$ & $<0.05^{\ddagger}$ & $4 \pm 1$ & $3 \pm 1$ & $\leq 0.001^{*}$ \\
\hline DHT $(n g / d l)$ & $12 \pm 2$ & $14 \pm 2$ & $18 \pm 4$ & $14 \pm 4$ & $\leq 0.01^{\ddagger}$ & $6 \pm 1$ & $6 \pm 1$ & $<0.05^{*}$ \\
\hline $\mathrm{E}_{2}(\mathrm{pg} / \mathrm{ml})$ & $43 \pm 5$ & $67 \pm 16$ & $53 \pm 14$ & $46 \pm 8$ & $>0.05$ & $33 \pm 4$ & $46 \pm 7$ & $>0.05$ \\
\hline $\mathrm{E}_{1}(p g / m l)$ & $45 \pm 6$ & $76 \pm 17$ & $48 \pm 7$ & $41 \pm 8$ & $<0.05^{\ddagger}$ & $18 \pm 3$ & $20 \pm 3$ & $\leq 0.01^{*}$ \\
\hline SHBG $(\mu g / d l)$ & $0.39 \pm 0.09$ & $0.54 \pm 0.13$ & $0.45 \pm 0.11$ & $0.42 \pm 0.11$ & $>0.05$ & $0.95 \pm 0.13$ & $0.94 \pm 0.09$ & $\leq 0.01^{*}$ \\
\hline DHEAS $(\mu g / d l)$ & $123 \pm 20$ & $140 \pm 26$ & $172 \pm 58$ & $113 \pm 24$ & $>0.05$ & $100 \pm 31$ & $93 \pm 26$ & $>0.05$ \\
\hline$F(\mu g / d l)$ & $10.8 \pm 1.8$ & $9.3 \pm 0.9$ & $10.3 \pm 1.7$ & $9.5 \pm 1.6$ & $>0.05$ & $11.1 \pm 2.5$ & $11.9 \pm 1.3$ & $>0.05$ \\
\hline$T / E_{2}$ & $1.1 \pm 0.1$ & $1.0 \pm 0.1$ & $1.2 \pm 0.2$ & $1.4 \pm 0.3$ & $>0.05$ & $0.5 \pm 0.1$ & $0.3 \pm 0.04$ & $\leq 0.01^{*}$ \\
\hline$A / E_{1}$ & $4.6 \pm 0.3$ & $3.1 \pm 0.3$ & $4.0 \pm 0.6$ & $4.5 \pm 0.5$ & $\leq 0.01^{\ddagger}$ & $3.9 \pm 0.7$ & $3.7 \pm 0.8$ & $>0.05$ \\
\hline
\end{tabular}

To convert A to nanomoles per liter, multiply by 0.0349 ; to convert $\mathrm{T}$ and uT to nanomoles per liter, multiply by 0.0347 ; to convert DHT to nanomoles per liter, multiply by 0.0344 ; to convert $E_{2}$ to picomoles per liter, multiply by 3.671 ; to convert $E_{1}$ to picomoles per liter, multiply by 3.699; to convert SHBG to micromoles per liter, multiply by 0.0344 ; to convert DHEAS to micromoles per liter, multiply by 0.02714 ; to convert $\mathrm{F}$ to micromoles per liter, multiply by 0.02759 . * PCO effect. ${ }^{\ddagger}$ Insulin effect.

fusion days were compared by paired $t$ tests in the normal women. These minimal changes in hormone levels in the normal women resulted in a failure to detect similar significant changes in the day 2 PCO women and the normal women compared with the two PCO groups. There were no significant changes in DHEAS or SHBG levels in the PCO groups or in the normal women. The mean plasma $F$ levels in the pools did not change significantly in any of the groups, suggesting that stress did not contribute to the findings (Table II). Mean plasma $P$ levels in the pools were in the follicular range, indicating the absence of recent ovulation (data not shown).

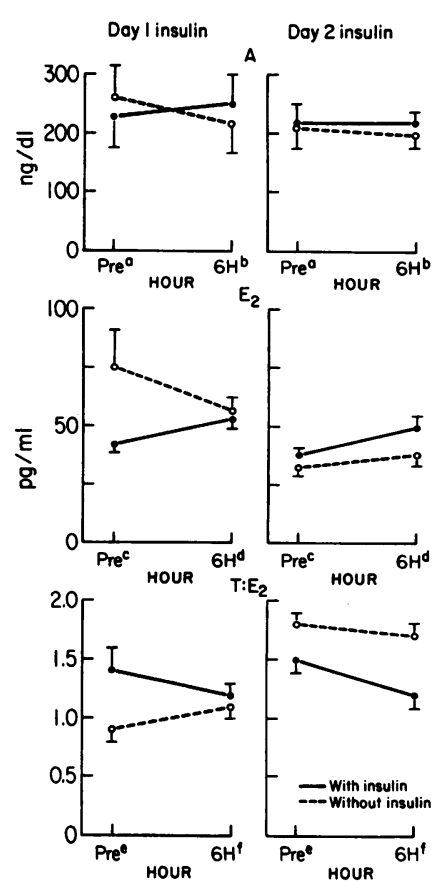

Figure 1. The effects of insulin infusion on study day 1 (left) and study day 2 (right) on mean \pm SEM prestudy (Pre), 6 $\mathrm{h}(6 \mathrm{H})$, and delta $(6 \mathrm{~h}$ minus prestudy), $A$ and $E_{2}$ levels and $T / E_{2}$ ratios in the $P C O$ women. ${ }^{a} P<0.05$ study day effect; ${ }^{b} P \leq 0.0016 \mathrm{~h}$ and delta insulin effect, and $P$ $\leq 0.01$ delta study day effect; ${ }^{\mathrm{c}} P<0.05$ study day effect; ${ }^{\mathrm{d}} P$ $<0.05$ study day effect, $P$ $<0.05$ delta insulin effect, ${ }^{\mathrm{e} P}$ $\leq 0.01$ study sequence effect; ${ }^{f} P<0.056 \mathrm{~h}$ and delta study sequence effect. There are marked differences in the prestudy $A$ and $E_{2}$ levels on the two study days in the day 1 insulin PCO group (left) that do not occur in the day 2 insulin PCO group (right). To convert A to nanomoles per liter, multiply by 0.0349 ; to convert $E_{2}$ to picomoles per liter, multiply by 3.671 .
Gonadotropin secretion (Table III). There were no signifcant differences in any parameters of gonadotropin release between the two PCO groups. Mean plasma LH levels, LH pulse amplitude, and maximal LH responses to $\mathrm{GnRH}$ were significantly increased $(P<0.05-\leq 0.001)$ in PCO women compared with the normal women compatible with the increase in LH release characteristic of PCO $(1,2)$. LH pulse frequency and FSH release were similar in the PCO and the normal women.

There were significant study day effects in the two PCO groups for mean LH levels $(P<0.05)$, mean FSH levels $(P$ $\leq 0.01)$, and maximal FSH responses to $\mathrm{GnRH}(P<0.05)$; values for these parameters were lower on study day 2 . Similarly, there were significant decreases in mean LH $(P \leq 0.01)$ and FSH levels $(P<0.05)$ and maximal $\mathrm{LH}$ responses to GnRH $(P<0.05)$ on study day 2 in the day 2 insulin PCO

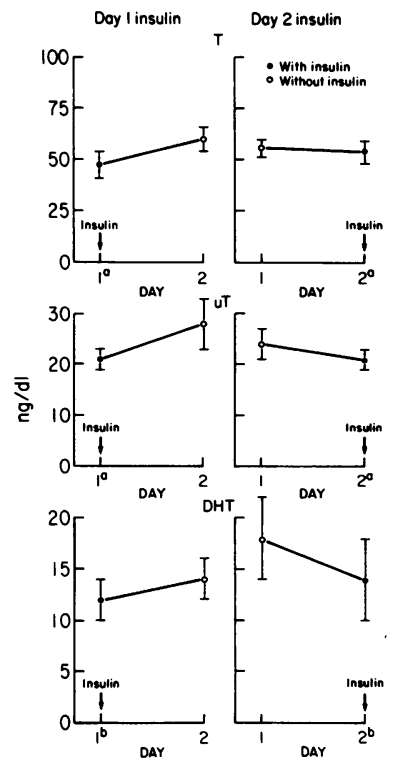

Figure 2. The effects of insulin infusion on mean \pm SEM plasma pool levels of T, uT, and DHT in the day 1 insulin PCO group (left) and day 2 insulin PCO group (right) on study day 1 and study day $2{ }^{a} P<0.05$ insulin effect, ${ }^{b} P$ $\leq 0.01$ insulin effect. To convert $T$ and $u T$ to nanomoles per liter, multiply by 0.0347 ; to convert DHT to nanomoles per liter, multiply by 0.0344 . 


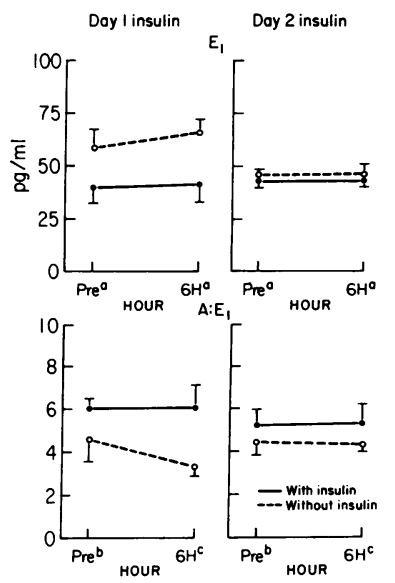

Figure 3. The effects of insulin infusion on study day 1 (left) and study day 2 (right) on mean \pm SEM prestudy (Pre), $6 \mathrm{~h}(6 \mathrm{H})$, and delta ( $6 \mathrm{~h}$ minus prestudy) $\mathrm{E}_{1}$ levels and $A / E_{1}$ ratios in the $P C O$ women. ${ }^{a} P \leq 0.01$ insulin effect, $P$ $<0.05$ day effect, $P>0.05$ all delta effects; ${ }^{b} P<0.05$ insulin effect; ${ }^{c} P \leq 0.01$ insulin effect, $P$ $>0.05$ all delta effects. In the day 1 insulin PCO group (left) there are marked increases in prestudy and $6 h E_{1}$ levels and marked decreases in prestudy and $6 \mathrm{~h} \mathrm{~A} / \mathrm{E}_{1}$ ratios on study day 2 without insulin infusion compared with study day 1 with insulin infusion. Similar differences do not occur in the day 2 insulin PCO group (right). To convert $\mathrm{E}_{1}$ to picomoles per liter, multiply by 3.699 .

women and the normal women. By paired $t$ tests, these decreases were significant for mean LH and FSH levels only in the day 2 PCO women and not the normal women, whereas maximal LH responses to GnRH tended to be lower but this change did not achieve statistical significance in either group. There were no other significant effects of insulin or of study sequence in the two PCO groups or the normal women.

\section{Discussion}

Insulin acutely increased $A$ and $E_{2}$ levels and decreased $T$, uT, and DHT levels in insulin-resistant women with PCO. In normal women, the only significant change in steroid levels during insulin infusion was an increase in $E_{2}$ levels; no changes in androgen levels were noted. The levels of insulin producing these changes were supraphysiologic and thus insulin may have been acting through the IGF-I receptor $(15,18)$. Insulin did not increase any parameters of gonadotropin release in PCO or normal women. Further, the significant decreases noted in $\mathrm{LH}$ and FSH release were confirmed to be secondary to study day in the two PCO groups. Such decreases did not occur in normal women. These spontaneous significant decreases in $\mathrm{LH}$ and FSH release thus appear to be a feature of
PCO and could substantially confound studies of gonadotropin release in this disorder (31).

In a previous study (22), insulin in similar doses also failed to increase $\mathrm{T}$ levels and decreased DHEAS levels in normal women. In our study, DHEAS levels did not decrease; this may have been related to the briefer duration of insulin administration. Conversely, Stuart and colleagues (23) found that lower levels of insulin increased $A$ levels in normal men and women and in three hyperandrogenic insulin-resistant women with acanthosis nigricans. A range of doses of insulin, however, did not alter T levels; DHEAS levels were not measured. Thus, even if the failure to detect increases in A levels in normal women was related to the dose of insulin used, our study is in agreement with previous ones, indicating that $T$ levels do not increase acutely with insulin administration in normal women.

The increases in sex hormone levels in PCO women noted with insulin infusion were probably the result of a direct insulin action on steroid secretion and/or metabolism, since these changes were independent of changes in gonadotropin release. Insulin clearly altered both androgen and estrogen levels in insulin-resistant women with PCO but only possibly increased $\mathrm{E}_{2}$ levels in normal women, suggesting that abnormalities associated with PCO augmented insulin effects on sex hormone levels. The decreases in T, uT, and DHT levels in the PCO women may have been the result of direct actions of insulin on steroidogenesis or, perhaps, alterations in hormone clearance such as steroid uptake by adipose tissue (37). These changes were not related to the decreases in gonadotropin levels noted on study day 2 in the PCO women because the randomized study design demonstrated that decreases in androgen levels also occurred with insulin infusion on study day 1 .

Sequence effects indicating a carryover action of insulin in the PCO women were significant only for the mean prestudy, 6-h, and delta $T / E_{2}$ ratios. However, the significant changes (insulin and/or day effects) in mean plasma prestudy $A, E_{2}$, and $E_{1}$ levels and $A / E_{1}$ ratios also suggested a carryover action of insulin, although the sequence effect did not achieve statistical significance. In the day 1 insulin PCO group, the levels of these steroids were substantially different in the day 2 prestudy sample ( $\sim 16 \mathrm{~h}$ after insulin infusion) from all time points in the day 2 insulin PCO group and from the study day 1 prestudy sample (i.e., before insulin infusion) in the day 1 insulin

Table III. Gonadotropin Secretion

\begin{tabular}{|c|c|c|c|c|c|c|c|c|}
\hline & \multicolumn{5}{|c|}{ PCO } & \multicolumn{3}{|c|}{ Normal } \\
\hline & Insulin day 1 & Control day 2 & Control day 1 & Insulin day 2 & $P$ & Control day 1 & Insulin day 2 & $P$ \\
\hline LH ( $\mu g /$ liter $)$ & $105 \pm 26$ & $90 \pm 21$ & $114 \pm 10$ & $98 \pm 9$ & $<0.05^{*}$ & $51 \pm 8$ & $46 \pm 5$ & $\leq 0.001^{\ddagger}$ \\
\hline FSH $(\mu g /$ liter $)$ & $219 \pm 16$ & $182 \pm 6$ & $313 \pm 25$ & $289 \pm 27$ & $\leq 0.01^{*}$ & $311 \pm 40$ & $300 \pm 41$ & $>0.05$ \\
\hline LH amp $(\mu g / \text { liter })^{\S}$ & $37 \pm 10$ & $34 \pm 9$ & $44 \pm 9$ & $36 \pm 4$ & $>0.05$ & $15 \pm 2$ & $14 \pm 2$ & $\leq 0.01^{\ddagger}$ \\
\hline FSH amp $(\mu g / \text { liter })^{\S}$ & $48 \pm 9$ & $39 \pm 1$ & $47 \pm 6$ & $43 \pm 7$ & $>0.05$ & 56 & 63 & $>0.05$ \\
\hline LH $(f / 6 h)^{\|}$ & $5.6 \pm 1.0$ & $5.4 \pm 0.9$ & $6.4 \pm 0.2$ & $6.6 \pm 0.7$ & $>0.05$ & $6 \pm 0.8$ & $4.8 \pm 0.7$ & $>0.05$ \\
\hline $\operatorname{FSH}(f / 6 h)^{\|}$ & $2.0 \pm 0.7$ & $1.0 \pm 0.4$ & $2.0 \pm 0.7$ & $2.8 \pm 1.2$ & $>0.05$ & $0.8 \pm 0.8$ & $0.6 \pm 0.4$ & $>0.05$ \\
\hline LH max ( $\mu g /$ liter $)^{\top}$ & $355 \pm 133$ & $352 \pm 121$ & $423 \pm 109$ & $278 \pm 45$ & $>0.05$ & $108 \pm 22$ & $77 \pm 6$ & $<0.05^{* *}$ \\
\hline FSH max $(\mu g / \text { liter })^{\pi}$ & $143 \pm 35$ & $92 \pm 21$ & $225 \pm 27$ & $162 \pm 22$ & $<0.05^{*}$ & $170 \pm 30$ & $126 \pm 14$ & $>0.05$ \\
\hline
\end{tabular}

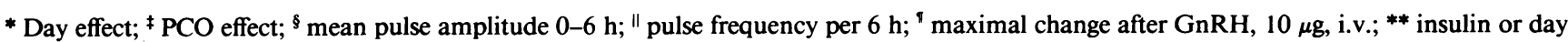
effect. 
PCO group (Figs. 1 and 3). Mean $\mathrm{A}$ and $\mathrm{E}_{2}$ levels were returning towards baseline by $6 \mathrm{~h}$ on study day $2(\sim 22 \mathrm{~h}$ after insulin infusion) in the day 1 insulin PCO group (Fig. 1). Such changes gave the appearance that these steroid levels were decreasing in the day 1 insulin PCO group on study day 2 (Fig. 1) and could have contributed to the significant delta values for these hormones. Mean $E_{1}$ levels and $A / E_{1}$ ratios were maximally different from all other values for these hormones in the 6-h sample ( $\sim 22 \mathrm{~h}$ after insulin infusion) on study day 2 in the day 1 insulin PCO group (Fig. 3).

Similar changes in mean plasma $A, E_{2}$, or $E_{1}$ levels or $A / E_{1}$ ratios were not noted in the day 2 insulin PCO group (Figs. 1 and 3). There were minimal changes in these hormone levels on study day 1 (e.g., no previous insulin infusion) in the day 2 insulin PCO group. Further, these different patterns of hormone change could not be ascribed to heterogeneity in the two PCO groups, since the women were randomly assigned to each group and day 1 prestudy hormone levels obtained before insulin infusion did not differ. Finally, it is unlikely that spontaneous day-to-day variation accounted for these changes, as only the day 1 insulin PCO group showed such changes and our previous studies have not found similar differences in PCO women on two consecutive study days without hormone administration (31). These findings strongly suggest that the changes in plasma $A, E_{2}$, and $E_{1}$ levels and $A / E_{1}$ ratios on study day 2 in the day 1 insulin PCO group reflected a carryover action of insulin. More prolonged insulin infusion will be required, however, to clarify this issue.

Insulin can increase A production (21) and aromatase activity (38) in human ovarian tissue in vitro; these actions could account for the increases in $A, E_{1}$, and $E_{2}$ levels and decreases in the aromatase precursor/product pairs, $A / E_{1}$ and $T / E_{2}$, that we observed during and/or after insulin infusion in vivo. Conversely, the decreases in T, uT, and DHT levels occurred acutely with insulin infusion on both study days and there was no evidence for a continued action of insulin. Such changes could have reflected alterations in hormone clearance rather than production, but this remains speculative because metabolic clearance rates were not determined. Alternatively, these decreases could represent enhancement of a putative 17-ketosteroid reductase deficiency (39), resulting in decreased ovarian and adrenal conversion of $A$ to $T$, although the simultaneous increase in $E_{2}$ levels argues against this possibility. The absence of similar decreases in our normal women and the failure of previous studies $(22,23)$ to find significant decreases in $\mathrm{T}$ levels, suggest that factors associated with PCO are required for these changes to be manifested.

Our failure to detect increases in more than one plasma androgen level (i.e., A) may have been related to the brief duration of the insulin infusion. Similarly, we could have failed to detect possible carryover actions of insulin in the normal women because they did not participate in the randomized study design. However, we also failed to detect differences in sex hormone or gonadotropin levels related to varying degrees of chronic endogenous hyperinsulinemia in obese and nonobese PCO and normal women (30). Further, Nestler and colleagues found (22) no increases in T, P, or LH levels in normal women for 12-16 h during, as well as $48 \mathrm{~h}$ after, infusion of similar doses of insulin. Finally, we were not able to cause hyperandrogenism with three weeks of experimentally induced moderate hyperinsulinemia in female rats (40). But we found a significant increase in ovarian [ $\left.{ }^{125} \mathrm{I}\right]-\mathrm{IGF}-\mathrm{I}$ binding sites suggesting that insulin upregulated IGF-I receptors (40).

Thus, although this study establishes that supraphysiologic doses of insulin can acutely and directly alter steroidogenesis in insulin-resistant PCO women, insulin did not consistently increase androgen levels, arguing against a simple causal relationship between hyperinsulinemia and hyperandrogenism in typical PCO. This is in agreement with the more complex relationships we have noted previously (26) between endogenous insulin levels and sex hormone levels in hyperandrogenic women. Considering the present and previous studies together, we propose an alternative mechanism for the association of hyperinsulinemia and hyperandrogenism in PCO. IGF-I rather than insulin appears to play a physiologic role in the regulation of gonadal steroidogenesis (18), but supraphysiologic amounts of insulin can act through the IGF-I receptor (15, $18,21)$. Further, increased LH release is the major stimulus to ovarian androgen secretion in PCO (41). Moderate hyperinsulinemia could thus act synergistically with the other hormonal disturbances of PCO, in particular LH hypersecretion, to enhance abnormal gonadal steroidogenesis by increasing ovarian sensitivity to ambient IGF-I levels via upregulation of IGF-I receptors (40). In the syndromes of extreme insulin resistance, however, it remains possible that profound longstanding hyperinsulinemia may be sufficient alone to produce hyperandrogenism.

\section{Acknowledgments}

The authors thank the nursing staff of the Mount Sinai Hospital General Clinical Research Center for their superb care of the study participants, Dr. E. Diamond, R. Szechter, R. Weiss, and A. Dobrjansky for technical assistance, the National Hormone and Pituitary Agency for providing reagents for the gonadotropin assays, Dr. T. Davies and Dr. E. Rayfield for critical review of the manuscript, and Anne Quartey for her skillful preparation of the manuscript. The authors are also indebted to Dr. John Mandeli for advice on the statistical analyses and to Dr. Ralph DeFronzo for assistance in establishing the euglycemic clamp technique.

This work was supported by grants from the Charles $\mathrm{H}$. Revson Foundation and the National Institutes of Health (HD-00608 and RR-00071).

\section{References}

1. Goldzieher, J. W. 1981. Polycystic ovarian disease. Fertil. Steril. 35:273-305.

2. Yen, S. S. C. 1980. The polycystic ovary syndrome. Clin. Endocrinol. 12:177-208.

3. Burghen, G. A., J. R. Givens, and A. E. Kitabchi. 1980. Correlation of hyperandrogenism with hyperinsulinemia in polycystic ovarian disease. J. Clin. Endocrinol. \& Metab. 50:113-116.

4. Pasquali, R., S. Ventruroli, R. Paradis, M. Capelli, N. Parenti, and N. Melchionda. 1982. Insulin and C-peptide levels in obese patients with polycystic ovaries. Horm. Metab. Res. 14:284-287.

5. Chang, R. J., R. M. Nakamura, H. L. Judd, and S. A. Kaplan. 1983. Insulin resistance in nonobese patients with polycystic ovarian disease. J. Clin. Endocrinol. \& Metab. 57:356-359.

6. Shoupe, D., D. D. Kumar, and R. A. Lobo. 1983. Insulin resistance in polycystic ovary syndrome. Am. J. Obstet. Gynecol. 147:588592.

7. Taylor, S. I., R. F. Dons, E. Hernandez, J. Roth, and P. Gorden. 1982. Insulin resistance associated with androgen excess in women 
with autoantibodies to the insulin receptor. Ann. Intern. Med. 97:851855.

8. Flier, J. S., R. C. Eastman, K. L. Minaker, D. Matteson, and J. W. Rowe. 1985. Acanthosis nigricans in obese women with hyperandrogenism: characterization of an insulin-resistant state distinct from the Type A and B syndromes. Diabetes. 34:101-107.

9. Dunaif, A., A. R. Hoffman, R. E. Scully, J. S. Flier, C. Longcope, L. J. Levy, and W. F. Crowley. 1985. The clinical, biochemical, and ovarian morphological features in women with acanthosis nigricans and masculinization. Obstet. Gynecol. 66:545-552.

10. Kahn, C. R., J. S. Flier, R. S. Bar, J. A. Archer, P. Gorden, M. M. Martin, and J. Roth. 1976. The syndromes of insulin resistance and acanthosis nigricans. $N$. Engl. J. Med. 294:739-745.

11. Imperato-McGinley, J., R. E. Peterson, E. Sturla, Y. Dawood, and R. S. Bar. 1978. Primary amenorrhea associated with hirsutism, acanthosis nigricans, dermoid cysts of the ovaries and a new type of insulin resistance. Am. J. Med. 65:389-395.

12. Huseman, C. A., A. J. Johanson, M. M. Varma, and R. M. Blizzard. 1979. Congenital lipodystrophy II. Association with polycystic ovarian disease. J. Pediatr. 95:72-74.

13. Barbieri, R. L., and K. J. Ryan. 1983. Hyperandrogenism, insulin resistance, and acanthosis nigricans syndrome: a common endocrinopathy with distinct pathophysiologic features. Am. J. Obstet Gynecol. 147:90-101.

14. Poretsky, L., D. Smith, M. Seibel, A. Pazianos, A. C. Moses, and J. S. Flier. 1984. Specific insulin binding sites in human ovarian stroma. J. Clin. Endocrinol. \& Metab. 59:809-811.

15. Poretsky, L., and M. F. Kalin. 1987. The gonadotropic function of insulin. Endocr. Rev. 8:132-141.

16. Havrankova, J., J. Roth, and M. Brownstein. 1978. Insulin receptors are widely distributed in the central nervous system of the rat. Nature (Lond.). 272:827-829.

17. Goodyer, C. G., L. de Stephano, W. H. Lai, H. J. Guyda, and B. I. Posner. 1984. Characterization of insulin-like growth factor receptors in rat anterior pituitary, hypothalamus, and brain. Endocrinology. 114:1187-1195.

18. Adashi, E. Y., C. E. Resnick, A. J. D'Ercole, M. E. Svoboda, and J. J. Van Wyk. 1985. Insulin-like growth factors as intraovarian regulators of granulosa cell growth and function. Endocr. Rev. 6:400420.

19. Wallum, B. J., G. J. Taborsky, D. Porte, D. P. Figlewicz, L. Jacobson, J. C. Beard, W. K. Ward, and D. Dorsa. 1987. Cerebrospinal fluid insulin levels increase during intravenous insulin infusions in man. J. Clin. Endocrinol. \& Metab. 64:190-194.

20. Adashi, E. Y., A. J. W. Hsueh, and S. S. C. Yen. 1981. Insulin enhancement of luteinizing hormone and follicle-stimulating hormone release by cultured pituitary cells. Endocrinology. 108:14411449.

21. Barbieri, R. L., A. Makris, R. W. Randall, G. Daniels, R. W. Kistner, and K. J. Ryan. 1986. Insulin stimulates androgen accumulation in incubations of ovarian stroma obtained from women with hyperandrogenism. J. Clin. Endocrinol. \& Metab. 62:904-910.

22. Nestler, J. E., J. N. Clore, J. F. Strauss, and W. G. Blackard. 1987. The effects of hyperinsulinemia on serum testosterone, progesterone, dehydroepiandrosterone sulfate, and cortisol levels in normal women and in a woman with hyperandrogenism, insulin resistance, and acanthosis nigricans. J. Clin. Endocrinol. \& Metab. 64:180-184.

23. Stuart, C. A., M. J. Prince, E. J. Peters, and M. J. Meyer. 1987. Hyperinsulinemia and hyperandrogenemia: in vivo androgen response to insulin infusion. Obstet. Gynecol. 69:921-925.

24. Barbieri, R. L., A. Makris, and K. J. Ryan. 1983. Effects of insulin on steroidogenesis in cultured porcine ovarian theca. Fertil. Steril. 40:90-101.

25. National Diabetes Data Group. 1979. Classification and diagnosis of diabetes mellitus and other diagnostic categories of glucose intolerance. Diabetes. 28:1039-1057.

26. Dunaif, A., M. Graf, J. Mandeli, V. Laumas, and A. Dobrjansky. 1987. Characterization of groups of hyperandrogenic women with acanthosis nigricans, impaired glucose tolerance, and/or hyperinsulinemia. J. Clin. Endocrinol. \& Metab. 65:499-507.

27. Kim, M. H., R. L. Rosenfield, A. H. Hosseinian, and H. G. Schneir. 1979. Ovarian hyperandrogenism with normal and abnormal histologic findings of the ovaries. Am. J. Obstet. Gynecol. 134:445452.

28. Moltz, L., R. Sorensen, A. Rommler, U. Schwartz, and J. Hammerstein. 1985. Polycystic ovaries: specific disease picture or nonspecific symptom? Geburtsh. Frauenheilkd. 45:107-114.

29. New, M. I., F. Lorenzen, A. J. Lerner, B. Kohn, S. E. Oberfield, M. S. Pollack, B. Dupont, E. Stoner, D. J. Levy, S. Pang, and L. S. Levine. 1983. Genotyping steroid 21-hydroxylase deficiency: hormonal reference data. J. Clin. Endocrinol. \& Metab. 57:320-326.

30. Dunaif, A., J. Mandeli, H. Fluhr, and A. Dobrjansky. 1988. The impact of obesity and chronic hyperinsulinemia on gonadotropin release and gonadal steroid secretion in the polycystic ovary syndrome. J. Clin. Endocrinol. \& Metab. 66:131-139.

31. Dunaif, A. 1986. Do androgens directly regulate gonadotropin secretion in the polycystic ovary syndrome? J. Clin. Endocrinol. \& Metab. 63:215-221.

32. DeFronzo, R. A., J. D. Tobin, and R. Andres. 1979. Glucose clamp technique: A method for quantifying insulin secretion and resistance. Am. J. Physiol. 237:E214-E223.

33. Kolterman, O. G., J. Insel, M. Saekow, and J. M. Olefsky. 1980. Mechanisms of insulin resistance in human obesity. Evidence for receptor and postreceptor defects. J. Clin. Invest. 65:1272-1284.

34. Pearson, B., M. D. Murphy, W. Engelberg, and C. J. Patte. 1963. Simple method for the determination of plasma corticoids. $J$. Clin. Endocrinol. \& Metab. 23:293-300.

35. Fleiss, J. L. 1986. The design and analysis of clinical experiments. John Wiley \& Sons, New York. 432.

36. Flier, J. S., K. L. Minaker, L. Landsberg, J. B. Young, J. Pallotta, and J. W. Rowe. 1982. Impaired in vivo insulin clearance in patients with severe target-cell resistance to insulin. Diabetes. 31:132135.

37. Deslypere, J. P., L. Verdonck, and A. Vermeulen. 1985. Fat tissue: a steroid reservoir and site of steroid metabolism. J. Clin. Endocrinol. \& Metab. 61:564-570.

38. Garzo, V. G., and J. H. Dorrington. 1984. Aromatase activity in human granulosa cells during follicular development and the modulation by follicle-stimulating hormone and insulin. Am. J. Obstet. Gynecol. 148:657-662.

39. Pang, S., B. Softness, W. J. Sweeney, M. New. 1987. Hirsutism, polycystic ovarian disease, and ovarian 17-ketosteroid reductase deficiency. N. Engl. J. Med. 316:1295-1301.

40. Poretsky, L., B. Glover, V. Laumas, M. Kalin, and A. Dunaif. 1988. The effects of experimental hyperinsulinemia on steroid secretion, ovarian $\left[{ }^{125} \mathrm{I}\right]$ insulin binding, and ovarian $\left[{ }^{125} \mathrm{I}\right]$ insulin-likegrowth-factor I binding in the rat. Endocrinology. 122:581-585.

41. Chang, R. J., L. R. Laugher, D. R. Meldrum, J. DeFazio, J. K. H. Lu, W. W. Vale, J. E. Rivier, and H. L. Judd. 1983. Steroid secretion in polycystic ovarian disease after ovarian suppression by a long-acting gonadotropin-releasing hormone agonist. J. Clin. Endocrinol. \& Metab. 56:897-903. 